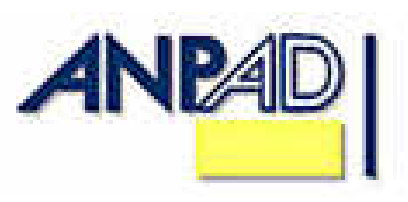

Available online at

http://www.anpad.org.br/bar

\title{
Strategic HR? A Study of the Perceived Role of HRM Departments in Brazil and Peru
}

\author{
Roberto Coda * \\ E-mail address: roberto.coda@uscs.edu.br \\ Universidade Municipal de São Caetano do Sul - USCS \\ São Paulo, SP, Brazil.
}

Ana Maria Roux Valentini Coelho César

E-mail address: rouxcesar@ mackenzie.br Universidade Presbiteriana Mackenzie São Paulo, SP, Brazil.

\section{Diógenes de Souza Bido}

E-mail address: dbido@mackenzie.br Universidade Presbiteriana Mackenzie São Paulo, SP, Brazil.

\section{Enrique Louffat}

E-mail address: elouffat@esan.edu.pe

Escuela de Administración de Negócios para Graduados - ESAN

Lima, Peru.

\section{ABSTRACT}

This study discusses the perceived role of the Human Resource Management Department and its perceived capacity of outstanding performance by comparing data collected in Brazil and Peru from employees of large organizations as well as participants in MBA programs at renowned schools. The non-probabilistic sample was composed of 416 Brazilian and 90 Peruvian respondents. The results point out that both in Brazil and Peru, the relevance attached to the HRM Department role for contributing to the future success of organizations does not correspond to its current capacity of performance. As such, in these realities the HRM Department has not yet made the qualitative leap that would enable its strategic role in organizations.

Key words: HRM department performance; human resource policies; HRM role effectiveness.

Received 13 February 2008; received in revised form 13 October 2008.

Copyright (C) 2009 Brazilian Administration Review. All rights reserved, including rights for translation. Parts of this work may be quoted without prior knowledge on the condition that the source is identified.

\footnotetext{
* Corresponding author: Roberto Coda

Rua Santo Antonio, 50, Centro, São Caetano do Sul, SP, 09521-160, Brazil.
} 


\section{INTRODUCTION}

In the management field, most contemporaneous studies highlight the competitive theme, introducing various approaches to competition and competitiveness (Cho \& Moon, 2000). As per the more generic definition (proposed by Stigler as cited in Newman, Eatwell, \& Milgate, 1998) competition is perceived as rivalry between individuals (or groups or nations) which always arises when two or more parties struggle for something that not everybody can achieve; the core element of competition is the freedom that traders have to use their resources, in whichever way they want, exchanging them at whatever price they wish. Assuming that competition involves the search for and retention of scarce factors, competitiveness is regarded as a means to surviving this competition, and it can be associated to performance (revealed competitiveness) or efficiency (potential competitiveness) - assumptions that are often questioned as they are insufficient to express the essence of the phenomenon when organizational past behaviors are analyzed, regardless of market and competition dynamisms.

The Resource Based View [RBV], one of the dominant theories of competitiveness analysis with a focus on company resources, has already been identified since the 50's in studies published by Selznick (as cited in Liu, 2005, p. 103) and Penrose (as cited in Lockett, 2005, p. 88). In this approach there are two fundamental concepts: resources, defined as tangible and intangible advantages, which are related to the firm in a semipermanent way, and capacities, regarded as a means to carry out different activities, depending on available resources (Skaates \& Sapãnnen, 2005). Human Resources are presented as one of the main factors in the search for competitiveness. Therefore, the HRM area is supposed to be strategic, situational and proactive in relation to business demands, offering support, mainly to operations strategy, which among the dimensions proposed by Kaplan and Norton (1997, 2000), is the one that depends most on people's resourcing, development and retention.

Recent studies developed in the area of Human Resources show that the HRM department has already become aware that people are part of the rare and hardly imitable capital. People are value generators. They are invaluable resources in the quest for competitiveness. Searching for, preparing and motivating them to grant their capital to the company is the major HRM strategic challenge. The core objective of this study is to identify to what extent people in organizations as stakeholders really consider the HRM area to be strategic, and how much they think it is prepared (in terms of current capacity) to cope with the challenges imposed on it. The research herein presented was conducted by instructors of MBA and MS Programs in major universities in Brazil and Peru, countries frequently labeled as having a typical Latin culture and sharing the same view in their entrepreneurial community towards the need for improving HRM departments role and policies in private and public organizations.

\section{THEORY AND HYPOTHESES}

This section includes a literature review on HRM classical functions as well as comments on cultural aspects that may influence the adoption or benchmark of HRM practices between different cultures.

\section{HR Classical Functions and Innovative Practices}

HRM classical functions may be understood as all activities and processes dealing with the professional life of an employee in an organization since his/her hiring, until his/her retirement or dismissal. Such processes are named people resourcing and retention, compensation and rewards, training and development, performance appraisal, benefits and relations with employees. All of them have undergone major changes during the last decades both in terms of their strategic relevance in the 
business context and the approaches used to conceive actions for their implementation in work settings. This section introduces a description of HRM functions as well as comments on the evolution of the strategic importance linked to people management in organizations.

\section{Resourcing and Staffing}

Millmore (2003) proposes a vertical integration of each HRM activity with company strategy priorities, a strategic position that outlined what was already being stressed 20 years ago (Pettigrew, Sparrow, \& Hendry, 1988). Recruiting and selection functions have remained relatively unchanged through time, still searching for the right person at the right place. Currently, the focus is the search for people to work in the organization, rather than to take over a specific job position, giving value to the set of human competences that are in line with companies' core competences.

\section{Development}

It has long been discussed that the development function may be beyond the training of technical competences or capacities demanded by market (Pettigrew, Sparrow, \& Hendry, 1988). The training and development function needs to be aligned to strategic factors, company policies and personality, time restrictions and willingness to change. The search for competitiveness speeds up the technological evolution process, which provokes ever larger skill gaps, requiring people and business units to be trained, looking forward to development and apprenticeship transfer (Berry \& Grieves, 2003).

\section{Benefits and Compensation}

Compensation systems strongly impact individual performance and company competitiveness, particularly when dimensions associated with intrinsic factors, such as status, independence and power are added to extrinsic traditional dimensions of motivational factors (Baron \& Kreps, 1999). From a purely economic point of view, work is considered as a commodity, with a price determined by the market. The point is that the worker is no longer labor work but rather human capital. Thus, the problem resides in identifying which level is considered adequate, by employer and employee, for the latter to assign its capital to the company.

\section{Relations with Employees}

Companies have been adopting family-friendly programs that seek to improve the relation between employee and family (Poelmans, Chinchilla, \& Cardona, 2003). These programs include work regimes with flexible hours, e-learning programs, available kindergarten facilities, seniors' support, sick leave to care for a family member, personal non-paid leaves, psychological services and support to expatriates. These practices have been valued as they enable the benefited people to better reconcile their personal needs with their companies' needs.

\section{Strategic Human Resource Management}

Human Resource Management [HRM] has been introducing significant changes over the last twenty five years (Gubman, 2004). An evolution can be seen since the times when thinking was quite nonstrategic (before the eighties, when the HRM area was merely the Personnel Department), going through the arising of functional strategies (in the eighties), the proposal of strategic capacity development (in the early nineties), up to the current vision, in which an effort from the area to be aligned with the company's strategic results prevails. Strategic proposals encompass the analysis of factors such as organizational culture, alignment between organizational core competences and human essential competences, employee commitment dimensions, among other factors, all focusing on the organization's future. People have began to be considered as one of the resources that contribute to 
competitive advantage, as human capital is unique, inimitable (people's intellectual capital is not easily replicated by competitors) and non-transferable (human capital is not easily acquired in the market) (Paauwe \& Boselie, 2003). In this scenario, in which the classical HRM functions (such as resourcing, people admittance and retention, staffing, appraisal and compensation) need to be aligned to the company and employees' performance (Gubman, 2004), the HRM focus is perceived as flexible, adapting to ongoing change and anticipating demands forecasted in future scenarios, in as much as the HRM functions support the business (Ashton, Haffender, \& Lambert, 2004). Research conducted in 2003/2004 in 30 English corporate organizations showed that HRM is poorly prepared to assume its strategic role. Criticism includes a lack of a robust theory backing the functions of the area, which is rather concerned with internal processes than with business strategy, that the area is poorly linked with the goals, needs and measures related to the business success. In other words, the HRM department is not regarded as a competitive advantage for organizations. Another survey carried out in 2003 by Accenture (Ashton, Haffender, \& Lambert, 2004) confirms these findings; among 1,000 leaders interviewed, only $34 \%$ evaluated the performance of the area as good, although $83 \%$ stated it was critical to the success of the business. From this last perspective, HRM should have three key capacities to be considered strategic. Firstly, it should distribute services related to HRM work processes, so all employees could have access to the internal and external channels related to them (communication). Secondly, the area should bring in HRM management consultancy services, performing as partners of executives, business units and business line managers. In this way, it would attend to the specific needs of each of the other departments of the company helping to develop core competences that are relevant to them and that may constitute business differentiating factors. Thirdly, the HRM department should provide more support and strategic services to the organization's senior management, an option foreseen as the future of the area, but which has yet to be established.

In a complementary study, Jacobs (2004) proposed five questions to analyze how the HRM department is evolving towards strategy: 1) Is the HRM manager effectively involved with or does it provide solid contributions to business strategy-related decisions? 2) Do managers from other departments regard the HRM department as an effective contributor to changing management within the organization? 3) Is the department agenda aligned with general business strategies? 4) Does the department participate in meetings with the CEO to provide advisory support in relation to the company's general strategies, not only to HRM-related issues? 5) Is the HRM department implementing any change in their focus to help the company reach its critical success points?

Also in relation to proposed actions to change the HRM department trajectory, Cakar, Bititci and MacBryde (2003) introduce an HRM management model that adopts an approach that is nearer to the engineering focus, as it is considered comprehensive by professionals from other departments which HRM interfaces with. The model assumes that HRM is a support process devised to assist to all of the other existing processes of the company in order to have these maximize their contributions to the accomplishment of business goals and strategy. HRM must keep an ongoing performance profile, having its goals regularly reviewed (the PDCA cycle as proposed by Deming) and offering support so that the other areas proceed likewise. For this purpose, the HRM department must monitor its performance impact on business results (as proposed by the Balanced Scorecard approach).

\section{Models for Evaluating the Human Resource Management Function}

This paper is based on Smilansky's contribution (1997) on the role of HRM Departments in public and private organizations as a result of research conducted in the UK during the nineties to assess the range of services that can be provided by an HRM department within an organization. He proposes an evaluation model built on perceptions of 978 heads of Human Resources and practitioners on the relative importance they attribute to five main clusters of HR internal services and their capability to deliver them effectively. Smilansky (1997) considers the overall purpose of the HR function to be to enable management to enhance the individual and collective contribution of people to the short-and long-term success of the enterprise, and the five major clusters of evaluation he used in his model were described as follows. 


\section{Strategy and Organization}

This includes the contribution of HR practitioners to the development and review of the organization's strategy, the development and review of organization structures and work processes to improve effectiveness as well as the review and improvement of organization culture and values to ensure that they support the long-term strategy.

\section{Resourcing}

This includes developing and maintaining resourcing strategy and plans to consider the strategic needs of the organization, recruiting new people, deploying people effectively within, releasing employees from the organization, and using contracted or temporary employees as part of the work force.

\section{Development}

This includes developing and maintaining resourcing strategy and plans to enhance individuals' and groups' performance in order to improve the organization's long-term competitive positioning; establishing performance planning and review processes; promoting long-term individual development; and promoting team development.

\section{Reward Management}

This includes developing and maintaining total remuneration strategy and plans; establishing levels of remuneration for jobs and people; developing and managing effective employee benefits and expenses, and, finally, paying employees.

\section{Relations with Employees}

These include both organizational development type services, such as developing and maintaining strategy, and plans for all employee relations activities; ensuring employees' commitment in times of change; and promoting effective internal communication to support the achievement of the organizational strategy. This topic also deals with more traditional industrial relations type services such as employee support services (counseling and welfare); ensuring compliance with organization policy and legal requirements; negotiation and consultation with groups and individuals, handling grievances and discipline, health and safety, and promoting equal opportunities.

Concerning HRM perspectives and evaluation models, 4 major ones have been developed in HRM literature (Martín-Alcázar, Romero-Fernández, \& Sánchez-Gardey, 2005) from its origins in the late 1970s. These authors propose a classification as follows. The first one is called universalistic and is mostly aimed at identifying the best HRM practices that are characterized by: (1) having demonstrated capacity to improve organizational performance and (2) having to be generalized; the second one is the contingency perspective which stresses the interactivity of variables in the HRM context, also denying the best practices notion; the third one is the configurational perspective, drawing attention to the fact that the HRM system has not only to be consistent with the environmental and organizational conditions, but also internally coherent; lastly, the contextual perspective is proposed, representing an important shift in the basis for analyzing the HRM function - this approach introduces a descriptive and global explanation, applicable to different environments and reflecting the particularities of geographical and industrial settings.

Considering the employees' point of view is also reported as an alternative and more recent method for analyzing the state of the HRM function (Gibb, 2001). This approach is particularly interesting for the purposes of this paper. The findings of a survey of 2,632 employees in 73 different companies in the UK indicate positive perceptions that include training and development, rewards and levels of 
personal motivation; noticeable areas of weakness in HRM exist in the management of staff levels, aspects of recruitment, communication and levels of morale in the organization as a whole (Gibb, 2001).

\section{Human Resource Management and Cultural Aspects}

Many global company managers have realized that there is no HRM one-sized solution that may be applied to all organization units, as there are cultural country differences, despite universal values set by headquarters and passed on to all local units. Managers have to deal with the challenge of rethinking and restructuring locally the services rendered by the HRM department, as defined by their head office, which frequently does not take into account the plurality of aspects of different units in the same organization (Fischer, 2003; Palthe \& Kossek, 2003), e.g. labor law differences.

Hofstede's model (1998), although criticized (Fang, 2003) is one of the most cited references in management analysis of a cross-cultural nature. It proposes a classification of culture types considering four dimensions (he gets to the point of proposing a fifth one, not mentioned herein): collectivism-individualism (level of priority designated to the person or group), power distance (level of acceptance of unequal power distribution), masculinity-femininity (extension in which culture searches for competitiveness and individual goals), aversion to uncertainty (extension in which people feel threatened by ambiguous situations). One of the Hofstede model's noteworthy factors might be that it is derived from a very large sample, formed by IBM worldwide collaborators. Basabe et al. (2002) discuss this original study, introducing a comparative chart with different countries based on Hofstede's four dimensions. Table 1 exhibits the positions of some South-American countries in relation to the four dimensions; the United States, France, Turkey and Japan's positions are also shown, only for the sake of a brief comparison with South-American countries, among which are Brazil and Peru.

Table 1: Hofstede's Cultural Dimensions in Some Countries

\begin{tabular}{|l|l|l|l|l|}
\hline Country & Individualism & Power distance & Masculinity & $\begin{array}{l}\text { Aversion to } \\
\text { uncertainty }\end{array}$ \\
\hline $\mathbf{3}$ & & & & \\
Brazil & $\mathbf{3 8}$ & $\mathbf{6 9}$ & $\mathbf{4 9}$ & $\mathbf{7 6}$ \\
\hline Argentina & 46 & 49 & 56 & 86 \\
\hline Chile & 23 & 63 & 28 & 86 \\
\hline Colombia & 13 & 67 & 64 & 80 \\
\hline & & & & \\
& $\mathbf{1 6}$ & $\mathbf{6 4}$ & $\mathbf{4 2}$ & $\mathbf{8 7}$ \\
\hline Peru & $\mathbf{9 1}$ & $\mathbf{4 0}$ & $\mathbf{6 2}$ & $\mathbf{4 6}$ \\
\hline United States & 71 & 68 & 43 & 86 \\
\hline France & 37 & 66 & 45 & 85 \\
\hline Turkey & 46 & 54 & 95 & 92 \\
\hline Japan & & & & \\
\hline
\end{tabular}

In Latin America and Japan, individualism rates are low compared to France and the United States; this means that these countries are more collectivist than France and the United States. In relation to acceptance of unequal power distribution, South American countries (except Argentina) have high indexes similar to France and Turkey. Notably the United States and Japan have lower indexes explained by the fact that these are societies that allow more social mobility. As for the masculinity dimension, characterized by a strong presence of competitiveness, a distribution of indexes around 50 is noticed, indicating some balance between femininity and masculinity, except for Colombia, the United States and Japan, which show a greater adhesion to masculine values. As per aversion to uncertainty, it is interesting to note that Brazil's index, though high, appears as the lowest among 
South-American countries; the rate of the United States is much lower than the remaining countries included in the Chart. An explanation for this observation may lie in the view of Brazil as a country of opportunities, more suited for entrepreneuring professionals.

These differences in relation to value considerations among countries show that the United States is quite different from South-American countries, as the indexes observed based on Hofstede's scale dimensions evolve towards the opposite way. This is especially interesting for this study, because most of the theory on Human Resource Management is generated in the American environment, based on practices and actions developed in and by American companies (domiciled there or not) with specific goals, in singular moments. HRM practices, probably more than other practices developed in other departments of the company, necessarily require to be adapted to local patterns, since the company is not a monolithic block (Palthe \& Kossek, 2003), having to stay alert in relation to the challenge of dealing with existing frontiers within its own organization (Fischer, 2003).

For this study, we did not collect data related to cultural aspects. Nevertheless, the study assumes that cultural differences between Brazil and Peru are significant as presented by Basabe et al. (2002). Consequently, it can be supposed that whether Latin countries do idealize and adopt the discourse of American authors on people management, the levels of strategic importance associated to HRM practices might be high in Brazil and Peru but, conversely, the current capacity (strategy implementation) of HRM departments in both countries could vary, reflecting existing cultural differences between Brazil and Peru.

This study compares data from Brazil and Peru, a country which, despite having demographic differences compared to Brazil, has a trend similar to the Brazilian one regarding the value dimensions proposed by Hofstede. From the theoretical discussion, which introduced HRM strategic importance, the innovating practices that support its performance and cultural difficulties to implement models generated in diverse cultural environments, the following hypotheses have been generated and brought up to the analysis performed herein:

Hypothesis 1. There are no differences between Brazil and Peru in relation to the strategic importance credited to the HRM department.

Hypothesis 2. There are no differences between Brazil and Peru in relation to the perception of the HRM current capacity to comply with its strategic functions.

Hypothesis 3. In Brazil, as well as in Peru, there are no differences between levels of strategic importance credited to the HRM department and the perception of its current capacity.

\section{RESEARCH METHODOLOGY}

\section{Measures}

The study developed between 2004 and 2006 was of an exploratory nature and utilized a quantitative methodology aimed at identifying the correlation between the importance credited to Human Resource practices to give support for future organizational success (IFFS), and the current capacity of this department to perform key HRM functions (CC) properly, as per the perception of working professionals in companies in the two South American countries, Brazil and Peru.

\section{Sample}

A non-probabilistic sampling procedure was applied to the composition of the sample. The sample was composed of 416 respondents in Brazil (367 cases left after suppressing missing information) and 90 in Peru, and followed parameters proposed by Hair, Anderson, Tatham and Black (1998) for 
statistical analysis. In Brazil, data was collected in different regions with respondents belonging to the South, North, Southeast and Northeast of the country. In Peru, data was collected in Lima and respondents, all students in MBA Programs, were managers in medium and large organizations considered key in the national economic scenario and located in different regions of the country.

\section{Data Collection Tools}

For the sake of data collection, Portuguese and Spanish versions of the questionnaire proposed by Smilansky (1997) were used. The tool presents items of the dimensions Strategy and Organization [SO], Resourcing [R], Development [D], Compensation and Benefits [CB] and Relations with Employees [RE], as presented in the theory section of this paper. To define these indicators related to roles and functions expected for the HRM department, assessment clusters were applied as proposed by Smilansky (1997). For data collection in Peru, the tool was translated into Spanish by one of the researchers, who is fluent in both languages. The identification and description of each variable are presented in Table 2. The variables were assessed in two different dimensions, being I for Importance for Future Success [IFS] evaluation and $\mathbf{C}$ for Current Capacity evaluation (Example: A2I - recruiting and selection people for the organization importance for future success; $\mathrm{A} 2 \mathrm{C}$ - recruiting and selection people for the organization current capacity of the HRM Department).

Table 2: Variables Identification

\begin{tabular}{|c|c|}
\hline VARIABLE & DESCRIPTION \\
\hline VSO & Strategy and Organization \\
\hline VSO1 & $\begin{array}{l}\text { Contribute to the overall strategy of the organization by providing generalist and specialist } \\
\text { information and advice }\end{array}$ \\
\hline VSO2 & $\begin{array}{l}\text { Develop and maintain an appropriate personnel strategy to support the overall strategy of the } \\
\text { organization }\end{array}$ \\
\hline VSO3 & $\begin{array}{l}\text { Enable the creation of an organization structure and work processes that maximize the } \\
\text { performance of people at work }\end{array}$ \\
\hline VSO4 & $\begin{array}{l}\text { Facilitate the development of organizational values and culture required to support its } \\
\text { strategy }\end{array}$ \\
\hline VSO5 & Facilitate external relations (e.g. purchasers, local authorities, educational institutions) \\
\hline VR & Resourcing \\
\hline VR1 & Develop and maintain workforce planning to support current and future requirements \\
\hline VR2 & Recruit and select people into the organization \\
\hline VR3 & Optimize the deployment of staff within the organization \\
\hline VR4 & Identify individual potential to develop and meet future resourcing requirements \\
\hline VR5 & Release people from the organization (e.g. retirement, redundancy) \\
\hline VR6 & Engage non-core and temporary staff \\
\hline VD & Development \\
\hline VD1 & Establish and maintain performance management \\
\hline VD2 & Establish opportunities to enhance individual capability (e.g. training) \\
\hline VD3 & Promote longer-term individual development processes \\
\hline VD4 & Facilitate team development process \\
\hline
\end{tabular}


(conclusion)

Table 2: Variables Identification

\begin{tabular}{|r|l|}
\hline \multicolumn{1}{|l|}{ VARIABLE } & \multicolumn{1}{|c|}{ DESCRIPTION } \\
\hline VCB & Compensation and Benefits \\
\hline VCB1 & Develop and maintain a reward strategy (e.g. pay, benefits) \\
\hline VCB2 & Establish and maintain the criteria for ensuring appropriate level of reward \\
\hline VCB3 & $\begin{array}{l}\text { Implement and maintain processes to define employees' terms and conditions of } \\
\text { employment }\end{array}$ \\
\hline VCB4 & Pay contracted employees and others \\
\hline VCB5 & Administer benefits and other payments \\
\hline VRE1 & $\begin{array}{l}\text { Develop and maintain commitment of employees in times of change (e.g. support change } \\
\text { programs) }\end{array}$ \\
\hline VRE2 & Promote effective communication within the organization \\
\hline VRE3 & $\begin{array}{l}\text { Provide counseling and welfare support for the mutual benefit of the organization and the } \\
\text { individual }\end{array}$ \\
\hline VRE4 & Ensure compliance with Personnel-related legislation and internal policies \\
\hline VRE5 & Provide processes for handling grievances and discipline \\
\hline VRE6 & $\begin{array}{l}\text { Consult and/or negotiate with employees and/or their representatives to facilitate } \\
\text { achievement of organizational goals }\end{array}$ \\
\hline VRE7 & Promote and ensure equality of opportunity \\
\hline ERE & Establish and maintain processes for ensuring health and safety at work \\
\hline
\end{tabular}

\section{Scales}

Respondents evaluated the IFFS (importance for future success) and the CC (current capacity) in two distinctive scales for each variable indicator and in each of the five proposed dimensions, totaling 28 items. This procedure thus originated 56 different variables (28 IFFS related and 28 CC related). The IFFS and the CC scales were both ordinal, with 5 grades. The following grades for the IFFSrelated scale were considered: 1 (critical), 2 (very important), 3 (important), 4 (possibly helpful) and 5 (irrelevant); for the CC-related scale the grades were: 1 (exceptionally good), 2 (very good), 3 (good), 4 (reasonable), 5 (poor). 


\section{Data Analysis}

Data was analyzed first using frequencies distribution on existing scales of the survey questionnaire using the Smilansky model (Smilansky 1997) and identifying score differences between Brazil and Peru in choice percentages for each variable in each researched dimension. Mean values for each variable were also calculated as a way for testing eventual differences in this measure between Brazil and Peru. We used the Wilcoxon rank sum test for finding the difference between two medians, a widely used non-parametric procedure for testing differences between the medians of two populations suitable for data not revealing a normal distribution (Levine \& Krehbiel, 2003; Moore, McCabe, Duckworth, \& Sclove, 2006, p. 731). The aforementioned statistics were run through the SPSS (Statistical Package for Social Sciences) version 13.0 software.

\section{RESULTS AND DISCUSSION}

\section{Demographics}

Among the Brazilian respondents, 59\% were men and $32 \%$ women; and $48 \%$ of the respondents had more than 10 years work experience. In terms of work area, $18 \%$ of respondents belonged to the HRM department, $29 \%$ to the Administrative department, 24\% to the Commercial department and 19\% were from the Back-end Area (production line/operational); 49\% had management positions, 9\% were consultants and $31 \%$ did not have management or supervision functions, performing as technical analysts with a university degree. In terms of Type of Company, $13 \%$ of the respondents worked in public companies, $33 \%$ in national companies and $45 \%$ in multinationals; $66 \%$ of the research respondents operated in large companies (annual gross income of over US\$20 million). Of the Peruvian respondents, $60 \%$ were men and $40 \%$ women; $29 \%$ of respondents had more than 10 years work experience; $2.9 \%$ of the respondents were from the HRM department, $50 \%$ from the Administrative department, $1.1 \%$ from the Commercial department and $20 \%$ were from the Back-end Area (production line/operational); 37\% had management positions, $13 \%$ were consultants and $50 \%$ did not have management or supervision functions, operating as technical analysts with a university degree. In terms of Type of Company, $32 \%$ of respondents performed in public companies, $61 \%$ in national companies and 7\% in multinationals; $18 \%$ of the research respondents worked in large companies (annual gross income of over US\$20 million).

Although there are differences in some of the demographic variables considered for the samples collected in Brazil and Peru, other similar studies conducted in Brazil revealed that demographic differences did not significantly interfere in the overall tendency of the results (Coda, Cesar, Bido, \& Louffat, 2007).

\section{HRM Departments - Importance to Organizational Future Success - [IFFS]}

Regarding the IFFS evaluation and comparison of Brazilian to Peruvian results, a mean for all the 28 items was calculated, and, subsequently, the Wilcoxon rank sum test was applied to verify the hypothesis of equality between the means. The items that did not present significant differences in their means were put together, being organized and included in Table 3, considering two major categories: higher and lower importance. As per analysis of results shown in Table 3, it is possible to accept the first hypothesis, since most of the indicators presented similar means.

Hypothesis 1. There are no differences between Brazil and Peru in relation to the strategic importance credited to the HRM area. 


\section{Common Aspects between Brazil and Peru in Relation to the Importance of HRM Departments to Organizational Future Success}

As for the Strategy and Organization dimension, both Brazilian and Peruvian respondents give more importance to the item VSO2I (Develop and maintain an appropriate personnel strategy to support the overall strategy of the organization). This shows that the discourse on strategy is equally valuated in both countries. There is also an agreement in relation to the item of lesser importance of this dimension, VSO5I (Facilitate external relations: purchasers, local authorities, educational institutions, etc.). This fact suggests that in both countries the HRM department is not seen as a communication agent between the company and its external environment. Concerning the Resourcing dimension, respondents only agreed in relation to the less important item VR6I (Engage non-core and temporary staff). This is particularly interesting because the Resourcing items depend on market supply and demand; items with different means are precisely related to people relocation and dismissal, aspects related to labor law issues. In the Development dimension, there was an agreement in relation to only one aspect, considered of major importance - VD2I (Establish opportunities to enhance individual capability, e.g. training). There was no agreement in terms of long term development processes, either individual or group-related, which are more strategic as they imply preparation for future demand. In relation to the Compensation and Benefits dimension, there was a coincidence of opinions as for the items of major importance- VCB1I (Develop and maintain a reward strategy); VCB4I (Pay contracted employees and others), and the item of lesser importance VCB3I (Implement and maintain processes to define employee's terms and conditions of employment). The less important item is the most strategic, as it is related to compensation and variable work condition aspects. The item selected in both countries as the most strategic is exactly HRM operational performance. Relations with employees was only agreed upon by respondents regarding the item of less importance, the VRE5I (Provide processes for handling grievances and discipline). Notably, this item was considered irrelevant in both countries as it is the one that represents the Power distance dimension, which was high in both countries; this fact probably means that there is a general acceptance that only a few people hold power, therefore, discipline rules and space for negotiation and claims are clearly defined.

Table 3: Analysis of Means Regarding Importance for Future Success - IFFS

\begin{tabular}{|c|c|c|c|}
\hline \multicolumn{2}{|c|}{ HR functions or roles } & \multirow{2}{*}{$\begin{array}{l}\text { Brazil } \\
\text { VEO2I (1.93) }\end{array}$} & \multirow{2}{*}{$\begin{array}{l}\text { Peru } \\
\text { VEO1I }(2.13)= \\
\text { VEO2I }(2.06)= \\
\text { VEO3I }(2.03)= \\
\text { VEO4I }(2.06)\end{array}$} \\
\hline \multirow{5}{*}{$\begin{array}{l}\text { Major } \\
\text { importance }\end{array}$} & Strategy and organization & & \\
\hline & Resourcing & $\begin{array}{l}\text { VR1I }(2.00)= \\
\text { VR2I }(1.99)= \\
\text { VR4I }(1.94)\end{array}$ & VR3I (2.31) \\
\hline & Development & VD2I (1.95) & $\begin{array}{l}\text { VD1I }(1.98)= \\
\text { VD2I }(2.03)= \\
\text { VD3I }(2.08)= \\
\text { VD4I }(1.95)\end{array}$ \\
\hline & Compensation and benefits & $\begin{array}{l}\text { VCB1I }(1.83)= \\
\text { VCB4I }(1.88)\end{array}$ & $\begin{array}{l}\text { VCB1I }(2,04)= \\
\text { VCB2I }(2.11)= \\
\text { VCB4I }(2.01)= \\
\operatorname{VCB} 5 I(2.00)\end{array}$ \\
\hline & Relations with employees & VRE2I (1.81) & VRE4I (1.86) \\
\hline
\end{tabular}


(conclusion)

Table 3: Analysis of Means Regarding Importance for Future Success - IFFS

\begin{tabular}{|l|l|l|l|}
\hline \multicolumn{1}{|l}{ HR functions or roles } & Brazil & Peru \\
\hline \multirow{4}{*}{$\begin{array}{l}\text { Lesser } \\
\text { importance }\end{array}$} & Strategy and organization & VEO5I (2.64) & VEO5I = 2.35 \\
\cline { 2 - 4 } & Resourcing & VR6I (3.48) & $\begin{array}{l}\text { VR5I (3.39) }= \\
\text { VR6I (3.38) }\end{array}$ \\
\cline { 2 - 4 } & Development & VD4I (2.21) & \\
\cline { 2 - 4 } & Compensation and benefits & VCB3I (2.25) & VCB3I (2.49) \\
\cline { 2 - 4 } & Relations with Employees & VRE5I (2.42) & VRE6I $(2.93)$ \\
\hline
\end{tabular}

Note: Values in parentheses are sample means and the equal sign indicates that the difference between the means was not significant applying Wilcoxon test with a 5\% significance probability. The sets of items are presented in the table with means of extreme values. It should be borne in mind that $1=$ maximum and $5=$ minimum for each $\mathrm{HR}$ function or role.

\section{Differences between Brazil and Peru in relation to the Importance of HRM Departments for Organizational Future Success}

Although there were various points in common in the opinion of Brazilian and Peruvian respondents, there was no unanimity and the main points about which they differ are highlighted as follows. In the Resourcing dimension Brazilians gave more importance to items VR1I (Develop and maintain workforce planning to support current and future requirements), VR2I (Recruit and select people into the organization) and VR4I (Identify individual potential to develop and meet future resourcing requirements). The item considered most important to the Peruvians was VR3I (Optimize the deployment of staff within the organization). This difference in relation to the importance given to Resourcing items shows that the Brazilian respondents, at least at a discourse level, more than the Peruvians, think the Resourcing function is strategic, as they consider future demand variables to be more important; Peruvian respondents give more importance to people's internal reallocation, a short term and more operational measure. As for Relations with Employees, Brazilians attributed more importance to item VRE2I (Promote effective communication within the organization), whilst Peruvians thought item VRE4I (Ensure compliance with Personnel-related legislation and internal policies) was more important. It is interesting to note that Brazilians considered it important to have an internal communication strategy, but not the maintenance of an external relationship with the community, as previously pointed out. The fact that Peruvians attributed more importance to labor law issues indicates that internal policies for people management should be associated to the country's labor law aspects.

Accomplishing a general analysis of results in the IFFS scale, it is worth noting that the highest means are verified with indicators related to the importance of the relation between HRM strategy with the company business strategy, with people training and retention and, finally, with efficient communication processes. It is also remarkable how much importance is given to communication, as it is exactly due to this process that people have access to information on business strategy.

\section{HRM Departments - Descriptive Analysis of Current Capacity to Perform Key HRM Functions - $[\mathrm{CC}]$}

The procedure applied on the preparation of Table 4 was exactly the same applied to preparing Table 1: means calculated and grouped when differences were not significant in the Wilcoxon rank sum test. By examining the analysis of the results shown in Table 4, it is possible to accept the second hypothesis, since most of the indicators presented similar means.

Hypothesis 2. There are no differences between Brazil and Peru in relation to the perception of the HRM current capacity to comply with its strategic functions. 


\section{Common Aspects between Brazil and Peru in Relation to the Current Capacity to Perform Key HRM Functions}

For the Strategy and Organization dimension, both Brazilian and Peruvian respondents evaluate that their organizations currently have a low capacity in relation to the following items: VSO2C (Develop and maintain an appropriate personnel to support the overall strategy of the organization); VSO3C (Enable the creation of an organization structure and work processes to maximize the performance of people at work); VSO4C (Facilitate the development of organizational values and culture required to support its strategy); VSO5C (Facilitate external relations: purchasers, local authorities, educational institutions, etc.). The gap between the importance attributed and current capacity in relation to the development of an HRM strategy to support business strategy shows that, in both countries, the reality of a strategic HRM department has not been materialized yet; whether a strategic role for the department is recognized, though not implemented, all the remaining HRM strategic actions are compromised as they are isolated actions, disconnected from overall business strategy.

Table 4: Analysis of Current Capacity Averages - CA

\begin{tabular}{|c|c|c|c|}
\hline \multicolumn{2}{|c|}{ HR Functions or Roles } & Brazil & Peru \\
\hline \multirow{5}{*}{$\begin{array}{l}\text { Higher } \\
\text { current } \\
\text { capacity }\end{array}$} & Organization and strategy & & VEO1C (2.83) \\
\hline & Resourcing & VR2C (3.09) & $\begin{array}{l}\operatorname{VR} 1 C(3.29)= \\
\operatorname{VR} 2 C(3.34)= \\
\operatorname{VR} 3 C(3.27)= \\
\operatorname{VR} 4 C(3.14)\end{array}$ \\
\hline & Development & VD2C (3.23) & $\begin{array}{l}\text { VD1C }(2.87)= \\
\text { VD2C }(2.97)= \\
\text { VD3C }(3.05)= \\
\text { VD4C }(3.00)\end{array}$ \\
\hline & Compensation and benefits & VCB4C (1.97) & VCB4C (2.29) \\
\hline & Relations with Employees & VRE4C (2.49) & $\begin{array}{l}\text { VRE4C }(2.74)= \\
\operatorname{VRE} 8 C(2.78)\end{array}$ \\
\hline \multirow{5}{*}{$\begin{array}{l}\text { Lower } \\
\text { current } \\
\text { capacity }\end{array}$} & Strategy and organization & $\begin{array}{l}\text { VEO1C }(3.51)= \\
\operatorname{VEO} 2 C(3.50)= \\
\operatorname{VEO} 3 C(3.55)= \\
\operatorname{VEO4C~}(3.42)= \\
\operatorname{VEO5C}(3.52)\end{array}$ & $\begin{array}{l}\text { VEO2C }(2.95)= \\
\text { VEO3C }(2.90)= \\
\text { VEO4C }(3.03)= \\
\text { VEO5C }(3.03)\end{array}$ \\
\hline & Resourcing & $\begin{array}{l}\text { VR3C }(3.51)= \\
\operatorname{VR} 4 C(3.61)= \\
\operatorname{VR} 5 C(3.53)= \\
\operatorname{VR} 6 C(3.50)\end{array}$ & $\begin{array}{l}\operatorname{VR} 5 C(3.63)= \\
\operatorname{VR} 6 C(3.58)\end{array}$ \\
\hline & Development & VD3C (3.68) & \\
\hline & Compensation and benefits & $\begin{array}{l}\operatorname{VCB} 1 C(3.41)= \\
\operatorname{VCB} 2 \mathrm{C}(3.48)= \\
\operatorname{VCB} 3 \mathrm{C}(3.31)\end{array}$ & $\begin{array}{l}\operatorname{VCB} 1 C(3.07)= \\
\operatorname{VCB} 2 \mathrm{C}(3.15)= \\
\operatorname{VCB} 3 \mathrm{C}(3.08)\end{array}$ \\
\hline & Relations with Employees & VRE7C (3.58) & $\begin{array}{l}\operatorname{VRE5C}(3.40)= \\
\operatorname{VRE6C~}(3.49)\end{array}$ \\
\hline
\end{tabular}

Note: Values in parentheses are sample means and the equal sign shows that the difference between the means was not significant applying Wilcoxon's test with a 5\% significance probability. The sets of items are presented in the table with means of extreme values. It should be borne in mind that $1=$ exceptionally good and $5=$ poor capacity, for each HR function or role.

With regard to the Resourcing dimension, respondents evaluated the VR2C (Recruit and select people into the organization) as an item with higher current capacity. This aspect was expected to be higher as it is one of the most clear HRM roles. Brazilians and Peruvians also agreed on the lower 
capacity items VR5C (Release people from the organization (e.g. retirement, redundancy) and VR6C (Engage non-core and temporary staff). Temporary employee admission had a low capacity, but it was not considered important for company success. Therefore, it was not a point of concern. Regarding the dismissal process, it could have a higher implementation capacity, as companies would need to be better prepared to perform dismissal processes, considering the issue of competitiveness related to human capital. In relation to the Development dimension, both Brazilians and Peruvians evaluated VD2C (Establish opportunities to enhance individual capability, e.g. training) as the item with the highest capacity; this is also an aspect considered operational, frequently outsourced by people. There was an overall agreement as to the Compensation and Benefits dimension: the item with the highest current capacity, VCB4C (Pay contracted employees and others), as well as items with lower current capacity - VCB1C (Develop and maintain a reward strategy, e.g. pay, benefits), VCB2C (Establish and maintain the criteria for ensuring appropriate level of reward) and VCB3C (Implement and maintain processes to define employees' terms and conditions of employment). This dimension proves the subject of day to day discussions within organizations (based on common sense): strategic compensation systems, highly stressed in the organizational discourse, are not developed. As for the Relations with Employees dimension, there was an agreement between respondents regarding the highest current capacity item -VRE4C (Ensure compliance with Personnel-related legislation and internal policies). This result was expected since respondents mostly worked at large and mediumsized companies, where the HRM department is structured and labor rights are observed because they are frequently inspected.

\section{Differences between Brazil and Peru in relation to the Current Capacity to Perform Key HRM Functions}

Although there are various points in common in Brazilian and Peruvian respondents' opinions, noteworthy differences are presented as follows. Strategy and Organization - Brazilians did not cite any item as having high current capacity, whilst Peruvians indicated item VSO1C (Contribute to the overall strategy of the organization by providing generalist and specialist information and advice). It is remarkable that though Peruvians did not admit the existence of an adequate people management strategy that provides support to company general strategy, they recognize that the department performs a consultancy role in specialized and general subjects. This performance is coherent with the idea of HRM decentralization, a procedure that has been widely proposed, as it draws the department near to effective demands from company sectors and units. Development - Peruvians did not cite any item as having low capacity, but Brazilians indicated item VD3C (Promote longer-term individual development processes) in this respect. The fact that this item was not noticed as having been implemented in companies based in Brazil confirms a gap between strategic discourses and practice, as this item is associated with the development of competences for future demands. Relations with Employees - While Brazilians regarded item VRE7C (Promote and ensure equality of opportunity) as having lower current capacity, Peruvians evaluated this way items VRE5C (Provide processes for handling grievances and discipline) and VRE6C (Consult and/or negotiate with employees and/or their representatives to facilitate the achievement of organizational goals). When the importance of item VRE5C was analyzed, it was noticed that among Peruvians it was low - it was considered that this evaluation might be justified by the Power distance dimension. Although it cannot be surely stated, it might be that its low current capacity has something to do with the same question as well.

Considering a general analysis of results on the $\mathrm{CC}$ scale, it can be noted that the lower means (and thus, with lower current capacity) result from indicators related to structures that maximize performance, employee strategic compensation and items related to employee motivation, such as equal opportunities and welfare. 


\section{Perceived Gaps (\%CC - \%IFFS)}

Hypothesis 3. In Brazil, as well as in Peru, there are no differences between levels of strategic importance credited to the HRM department and the perception of the department's current capacity.

To respond to this third hypothesis, an analysis of the difference between what has been actually performed (CC - current capacity) and what would be critical, i.e., what is important for the future success of the department to execute (IFFS), is provided. Considering only the addition of frequencies in numbers 1 and 2 in each of the assessment scales (higher valuation in each scale), the results achieved are presented in Table 5 .

Table 5: Presentation of Results by Indicator in Percentages

\begin{tabular}{cccccccc}
\hline \multirow{2}{*}{ Item } & \multicolumn{2}{c}{ Brazilian R espondents } & \multicolumn{2}{c}{ Peru vian Respondents } & DIF_B razil - \\
\cline { 2 - 6 } & IFFS & CC & DIF_B razil & IFFS & C C & D IF_Peru & D IF_Peru \\
\hline VSO 1 & $68,5 \%$ & $14,5 \%$ & $-54,0 \%$ & $72,4 \%$ & $32,6 \%$ & $-39,8 \%$ & $-14,2 \%$ \\
VSO 2 & $79,7 \%$ & $18,8 \%$ & $-60,9 \%$ & $79,3 \%$ & $31,0 \%$ & $-48,3 \%$ & $-12,6 \%$ \\
VSO 3 & $73,7 \%$ & $12,1 \%$ & $-61,6 \%$ & $57,0 \%$ & $37,9 \%$ & $-19,1 \%$ & $-42,5 \%$ \\
VSO 4 & $64,0 \%$ & $17,2 \%$ & $-46,8 \%$ & $69,0 \%$ & $31,0 \%$ & $-38,0 \%$ & $-8,8 \%$ \\
VSO 5 & $48,2 \%$ & $17,8 \%$ & $-30,4 \%$ & $57,0 \%$ & $27,6 \%$ & $-29,4 \%$ & $-1,0 \%$ \\
VR 1 & $73,3 \%$ & $18,3 \%$ & $-55,0 \%$ & $44,8 \%$ & $65,1 \%$ & $20,3 \%$ & $-75,3 \%$ \\
VR 2 & $75,1 \%$ & $25,6 \%$ & $-49,5 \%$ & $49,4 \%$ & $12,6 \%$ & $-36,8 \%$ & $-12,7 \%$ \\
VR 3 & $67,7 \%$ & $15,6 \%$ & $-52,1 \%$ & $64,7 \%$ & $17,6 \%$ & $-47,1 \%$ & $-5,0 \%$ \\
VR 4 & $77,9 \%$ & $15,5 \%$ & $-62,4 \%$ & $61,6 \%$ & $27,9 \%$ & $-33,7 \%$ & $-28,7 \%$ \\
VR 5 & $32,2 \%$ & $15,3 \%$ & $-16,9 \%$ & $9,5 \%$ & $46,4 \%$ & $36,9 \%$ & $-53,8 \%$ \\
VR 6 & $20,2 \%$ & $14,9 \%$ & $-5,3 \%$ & $13,8 \%$ & $9,3 \%$ & $-4,5 \%$ & $-0,8 \%$ \\
V D 1 & $73,8 \%$ & $20,0 \%$ & $-53,8 \%$ & $87,4 \%$ & $86,2 \%$ & $-1,2 \%$ & $-52,6 \%$ \\
V D2 & $80,4 \%$ & $24,4 \%$ & $-56,0 \%$ & $81,4 \%$ & $27,6 \%$ & $-53,8 \%$ & $-2,2 \%$ \\
V D 3 & $74,4 \%$ & $14,0 \%$ & $-60,4 \%$ & $82,8 \%$ & $26,4 \%$ & $-56,4 \%$ & $-4,0 \%$ \\
V D4 & $67,7 \%$ & $18,7 \%$ & $-49,0 \%$ & $86,2 \%$ & $32,6 \%$ & $-53,6 \%$ & $4,6 \%$ \\
V CB 1 & $83,1 \%$ & $19,8 \%$ & $-63,3 \%$ & $83,5 \%$ & $33,3 \%$ & $-50,2 \%$ & $-13,1 \%$ \\
V CB 2 & $78,5 \%$ & $17,7 \%$ & $-60,8 \%$ & $77,0 \%$ & $73,3 \%$ & $-3,7 \%$ & $-57,1 \%$ \\
V CB 3 & $62,3 \%$ & $19,3 \%$ & $-43,0 \%$ & $52,3 \%$ & $22,1 \%$ & $-30,2 \%$ & $-12,8 \%$ \\
V CB 4 & $77,1 \%$ & $73,1 \%$ & $-4,0 \%$ & $74,7 \%$ & $60,9 \%$ & $-13,8 \%$ & $9,8 \%$ \\
V CB 5 & $73,8 \%$ & $60,3 \%$ & $-13,5 \%$ & $74,7 \%$ & $46,5 \%$ & $-28,2 \%$ & $14,7 \%$ \\
VRE 1 & $79,2 \%$ & $17,5 \%$ & $-61,7 \%$ & $73,6 \%$ & $21,8 \%$ & $-51,8 \%$ & $-9,9 \%$ \\
VR 2 & $85,7 \%$ & $21,8 \%$ & $-63,9 \%$ & $82,8 \%$ & $23,0 \%$ & $-59,8 \%$ & $-4,1 \%$ \\
VRE 3 & $65,0 \%$ & $14,8 \%$ & $-50,2 \%$ & $59,8 \%$ & $19,5 \%$ & $-40,3 \%$ & $-9,9 \%$ \\
VRE 4 & $80,0 \%$ & $50,6 \%$ & $-29,4 \%$ & $81,6 \%$ & $48,3 \%$ & $-33,3 \%$ & $3,9 \%$ \\
VRE 5 & $55,7 \%$ & $21,7 \%$ & $-34,0 \%$ & $37,9 \%$ & $12,6 \%$ & $-25,3 \%$ & $-8,7 \%$ \\
VRE 6 & $67,0 \%$ & $22,6 \%$ & $-44,4 \%$ & $40,2 \%$ & $14,9 \%$ & $-25,3 \%$ & $-19,1 \%$ \\
VRE 7 & $75,5 \%$ & $16,0 \%$ & $-59,5 \%$ & $78,2 \%$ & $21,8 \%$ & $-56,4 \%$ & $-3,1 \%$ \\
VRE 8 & $78,2 \%$ & $43,3 \%$ & $-34,9 \%$ & $73,6 \%$ & $42,5 \%$ & $-31,1 \%$ & $-3,8 \%$ \\
& & & & & & &
\end{tabular}

In both cases, the differences are predominantly negative (current capacity lower than the importance of each item). On average, the differences obtained from the Brazilian respondents' answers were $-45.6 \%$ and the average of the differences of items answered by Peruvian interviewees was $-30.5 \%$. This shows that in Brazil and Peru the HRM current capacity does not correspond to the importance credited to the area.

Comparing differences between Brazilian respondents and Peruvian respondents (last column in Table 3), it can be noted that there are six items showing a gap of more than 20\%. Considering the Strategy and Organization dimension, item VSO3 (Enable the creation of an organization structure and work processes that maximize the performance of people at work) was the biggest gap observed. It is due to a high deficit between the importance that Brazilians give to the indicator and its current capacity, which is perceived as being very low in Brazil. Regarding the Resourcing dimension, the 
following items are remarkable: (1) VR1 (Develop and maintain workforce planning to support current and future requirements - ): in this item the difference between capacity and importance is negative for Brazil and positive for Peru. This is due to the Brazilians attributing more importance to the item and perceiving a lower current capacity; in the case of Peru, the situation is inverted; (2) VR4 (Identify individual potential to develop and meet future resourcing requirements): in this indicator Brazil presents a higher gap because Brazilians attributed more importance than Peruvians to the indicator, and a lower current capacity was also perceived; (3) VR5 (Release people from the organization e.g. retirement, redundancy - i): in this case, Brazilians attributed low importance to the indicator and low current capacity. Peruvians attributed more importance to the item than Brazilians and very high current capacity. In the Development dimension a bigger gap is seen between Brazilians and Peruvians in item VD1 (Establish and maintain performance management): whereas for Brazilians the attributed importance is high (73.8\%), the perceived current capacity is very low; the Peruvians perceived the importance and current capacity at almost the same high levels $(87.4 \%$ and $86.2 \%$, respectively). The analysis of the Compensation and Benefits dimension shows that the largest gap between the respondents was related to item VCB2 (Establish and maintain the criteria for ensuring appropriate level of reward): in this dimension, Brazilian and Peruvian behaviors followed the same trend verified in VD1 item. This difference in gaps shows that sometimes Brazilians have expectations that are higher than those of Peruvians for the HRM department in terms of its contribution to the organization's future success and more pessimistic perceptions in relation to the current capacity. The data does not allow any conclusions to be drawn about the gaps identified, but they suggest that future studies may be developed so that the factors related to them are investigated.

\section{CONCLUSION}

In relation to the HRM department's perceived image and its respective competence to deliver proposed services, the research results confirm the hypotheses of the study. Both in Brazil and Peru, the department is able to perform activities that can be classified as operational; however, strategic aspects are not perceived as being effectively performed. These findings contrast with current research on competences and roles for the HRM function and HRM professionals. Some researchers call for a courageous HR - one with attitude, translated into a clear point of view and position for the department performance (Meisinger, 2007). Others, taking into account the findings of a large survey conducted by David Ulrich and collaborators in the United States, Latin America, Europe, China and Australia, involving 9,798 respondents in 393 business units, discuss and validate the new identified set of key competences for an effective HR (Grossman, 2007). For the purpose of this paper it is interesting to note that this new set - credible activist, cultural steward, organizational designer, strategic architect, business ally and operational executor - stress mainly the strategic role of the HRM department. However, this last study reveals the point of view of HRM professionals, whilst our research presents the employee point of view. This aspect probably is the main reason for the gap between the strategic and operational frameworks for the HRM department performance.

As for the Strategy and Organization dimension, the Brazilians pointed out that the department is not able to cope with developing work structures to maximize either human or organizational performance. This suggests that HRM departments do not have adequate mechanisms to maximize human capital, a resource regarded as essential to business competitiveness. In the opinion of the Peruvians, the HRM department has a reduced capacity to facilitate external agent relations. This confirms the findings of Ashton, Haffenden and Lambert (2004) in England, pursuant to which executives state that the HRM department is concerned mostly with internal processes.

In the Resourcing dimension, the variable with lower capacity is not troublesome, as it involves labor work outsourcing, an issue that is still widely debated in organizational environments due to innumerable problems associated to it. 
With regards to the Development dimension, both Brazilians and Peruvians confer low current capacity to the process of promoting people development in the long term perspective. This is a reason for concern as it demonstrates that companies are still not prepared for enhancing employees' essential competences for better performance in the future. The Compensation and Benefits dimension shows that Brazilians and Peruvians have different opinions in relation to the low current capacity of the department. For Brazilians, the critical factor is associated with the absence of strategic compensation systems, whilst for Peruvians critical aspects are related to the definition of job terms and conditions. Both questions show that, as opposed to the ideas of Baron and Kreps (1999), companies are still not prepared to deal with human potential as a capital concept that needs to be remunerated and negotiated.

As for the Relations with employees dimension, Brazilians do not perceive the current capacity of HRM departments for providing counseling and welfare support for the mutual benefit of the organization and the individual. Peruvians, on the other hand, do not perceive the current capacity of HRM departments for providing processes for handling grievances and discipline. This shows that programs based on the improvement of mental health in organizations, as well as work conditions suitable to employees' expectations, as suggested by Poelmans, Chinchilla and Cardona (2003) are still far from reality.

As has been shown, HRM departments present difficulties in accomplishing major aspects that provide support for business strategies, such as promoting the implementation of an effective communication process, engagement and commitment of collaborators towards not only change but also with the intended organizational project, not to mention triggering people development in the long term.

The stage of the research here presented reveals a preliminary phase of investigating the role of HRM departments. Further developments can be achieved through the formulation and test of other hypotheses such as exploring in depth perceptions of HRM professionals only, mainly towards lower intensity of results connected to the current capacity of the department to meet its objectives and goals. Another possibility is to identify perceptions of respondents performing exclusively managerial duties. Whether the same tendencies were observed, another discussion can be established about the degree to which those managers are actually interested in work their interpersonal roles as managers of people in work settings. Besides those aspects, results also suggest another stream of investigation aimed at clarifying what could be the reasons obstructing the strategic role of HRM departments in organizations. Such studies could also consider the degree of competences demonstrated by HR professionals to meet these challenges. Therefore, there remains the need in Brazilian and Peruvian organizations to bring the HRM area out of the past, changing its role to a more strategic focus capable of coping with more modern trends, transforming it into an area that can provide adequate support to the overall organizational strategy.

Concluding this paper, we consider that this quantum leap for the HRM department represents a first step to be further developed by a broader comprehension that HRM professionals must acquire about their role in work organizations - every service delivered, as well as the image possessed by the department affect the overall behavior of the organization. They will have to recognize their role in minimizing agency theory conflicts - matching interests of principal -organization and agents employees.

\section{REFERENCES}

Ashton, C., Haffenden, M., \& Lambert, A. (2004). The "fit for purpose" HR function. Strategic HR Review, 4(1), 32-36. 
Baron, J. N., \& Kreps, D. M. (1999). Strategic human resources: frameworks for general managers. New York: John Wiley \& Sons, Inc.

Basabe, N., Paez, D., Valencia, J., Gonzalez, J. L., Rime, B., \& Diener, E. (2002). Cultural dimensions, socioeconomic development, climate, and emotional hedonic level. Cognition and Emotion, 16(1), 103-125.

Berry, C., \& Grieves, J. (2003). To change the way we do things is more important than the certificate on the wall: does investors in people represent an effective intervention strategy for organizational learning?. Learning Organization, 10(5), 294-304.

Cakar, F., Bititci, U. S., \& MacBryde, J. (2003). A business process approach to Human Resource management. Business Process Management Journal, 9(2), 190-207.

Cho, D. S., \& Moon, H. C. (2000). From Adam Smith to Michael Porter - evolution of competitiveness theory. Singapore: World Scientific Publishing Co. Pte. Ltd. and Asia-Pacific Business Series.

Coda, R., Cesar, A. M. R. V. C., Bido, D. S., \& Louffat, E. (2007). A new HR? Assessing the strategic role of HRM departments in Brazil and Peru. Proceedings of the Iberoamerican Academy of Management Conference. Santo Domingo, Dominican Republic, 5.

Fang, T. (2003). A critique of Hofstede's fifth national culture dimension. International Journal of Cross Cultural Management, 3(3), 347-369.

Fischer, K. (2003). Transforming HRM globally: the center of excellence approach. In Stopper, W. G. Current Practices. Human Resource Planning, 26(2), 5-11.

Gibb, S. (2001). The state of HRM: evidence from employees view of HRM system and staff. Employee Relations, 23(4), 318-336.

Grossman, R. J. (2007). New competencies for HR. HR Magazine, 52(6), 58-62.

Gubman, E. (2004). HR strategy and planning: from birth to business results. Human Resource Planning, 27(1), 13-23.

Hair, J. E., Jr, Anderson, R. E., Tatham, R. L., \& Black, W. C. (1998). Multivariate data analysis. Upper Saddle River: Prentice Hall.

Hofstede, G. (1998). Attitudes, values and organizational culture: distangling the concepts. Organization Studies, 19(3), 477-493.

Jacobs, R. J. (2004). Strategic HR: put yourself to the test. Strategic HR Review, 4(1), 3-3.

Kaplan, R. S., \& Norton, D. P. (1997). A estratégia em ação: Balanced Scorecard. São Paulo: Campus.

Kaplan, R. S., \& Norton, D. P. (2000). Utilizando o balanced scorecard como sistema gerencial estratégico. In Harvard Business Review. Medindo o desempenho empresarial. São Paulo: Campus.

Levine, D. M., \& Krehbiel, T. C. (2003). Business statistics: a first course. Upper Saddle River: Prentice-Hall.

Liu, T. L. (2005). Impacts on improvement of organizational synthetic value caused by social network relationships. Journal of American Academy of Business, 6(1), 102-109.

Lockett, A. (2005). Edith Penrose's legacy to the resource-based view. Management and Decision Economics, 26(2), 83-98. 
Martín-Alcázar, F., Romero-Fernández, P. M., \& Sánchez-Gardey, G. (2005). Strategic human resource management: integrating the universalistic, contingent, configurational and contextual perspectives. International Journal of Human Resource Management, 16(5), 633-659.

Meisinger, S. (2007). Latest competency study defines new HR roles. HRMagazine, 52(6), 12.

Millmore, M. (2003). Just how extensive is the practice of strategic recruitment and selection? Irish Journal of Management, 24(1), 87-108.

Moore, D. S., McCabe, G. P., Duckworth, W. M., \& Sclove, S. L. (2006). Estatística Empresarial. Rio de Janeiro: LTC.

Newman, P., Eatwell, J., \& Milgate, M. (1998). The new palgrave dictionary of economics. London: Macmillan.

Paauwe, J., \& Boselie, P. (2003). Challenging "strategic HRM" and the relevance of the institutional setting. Human Resource Management Journal, 13(3), 56-70.

Palthe, J., \& Kossek, E. E. (2003). Subcultures and employment modes: translating HRM strategy into practice. Journal of Organizational Change Management, 16(3), 287-308.

Pettigrew, A., Sparrow, P., \& Hendry, C. (1988).The forces that trigger training. Personnel Management, 20(12), 28-33.

Poelmans, S. A. Y., Chinchilla, N., \& Cardona, P. (2003). The adoption of family-friendly HRM practices. International Journal of Manpower, 24(2), 128-148.

Skaates, M. A., \& Seppänen, V. (2005). Market-oriented resource management in customer relationships. Qualitative Market Research, 8(1), 77-96.

Smilansky, J. (1997). The new HR. London: International Thomson Business Press. 